\title{
La religiosidad popular en los ejercicios de San Ignacio*
}

\author{
Víctor Codina, \\ CESIP, Oruro, Bolivia, \\ Centro de Reflexión Teológica, \\ San Salvador.
}

\section{Una hipótesis de trabajo}

Una primera impresión ante el texto y la práctica de los Ejercicios Espirituales de $S$. Ignacio (EE) nos llevara a la conclusión de que se dirigen prioritariamente a los sectores no populares de la sociedad y de la Iglesia, y que tanto su contenido como su estructura responden a una espiritualidad cultivada y casi elitista.

Esta impresión podría corroborarse con la Anotación 18 (EE. 18), donde se habla de acomodaciones de los EE. a personas rudas y sin letras, lo cual presupondria que los EE. requieren personas con ingenio y letras. Las mismas "Reglas para sentir con la Iglesia" (EE. 352-370), aunque evidentemente tratan de temas de religiosidad popular, tienen más bien una orientación apologética antierasmista y antiprotestante, más que directamente popular. ${ }^{1}$

Sin embargo, cabe preguntarse si estos datos, por ciertos que sean, agotan el tema de la relación entre los EE. y "lo popular," y más concretamente entre los EE. y la religiosidad popular.

El hecho de que Ignacio, al redactar el núcleo básico de los EE. fuera un simple laico, sin especial preparación cultural o teológica, ya nos puede indicar que su trasfondo religioso no puede ser muy diverso del popular.

La afirmación de Jerónimo Nadal de que Ignacio era populariter chrlstianus, un "cristiano popular," nos ofrece pistas para nuestro tema. ${ }^{2}$

La Autobiografta nos relata abundantes rasgos de la religiosidad popular de Ignacio: la confesión con su compantero de armas antes de la batalla de Pamplona, su devoción sencilla a San Pedro y sobre todo a Nuestra Sefiora, que le llevará a gastar parte del dinero cobrado del duque de Nájera en restaurar una imagen de Marfa "que estaba mal concertada," el deseo de imitar las proezas de santidad de Francisco y

\footnotetext{
- Ene ariculo fue publicado en portugues en Perspectiva Teologica, Belo Horizonte, Brasil.
} 
Domingo, la peregrinación a Jenusalén como objetivo primario de su nueva vida, la vigilia en Aránzazu y la vela de ammas en Montserrat, su vestido de pegregino con el bordón y la calabacita, su devoción en Tierra Santa y sus deseos de ver las huellas de la ascensión en el monte Olivete, su propósito de permanecer para siempre en los Santos Lugares... Todos estos rasgos y otros que pudieran antadirse, son signos inequivocos de la religiosidad popular de la época, que, como han notado los historiadores ignacianos, tienen connotaciones franciscanas. ${ }^{3}$

Por otra parte, la misma praxis de Ignacio de dar los EE. a gente sencilla, sobre todo en Alcalá y Salamanca, ¿no indica que existe una cierta connaturalidad entre el estilo de los EE. y la religiosidad popular?4

Entendemos por religiosidad popular la religión del pueblo, sobre todo del pueblo pobre y sencillo, tal como la Iglesia universal la entiende en sus recientes documentos (Evangelii nuntiandi 48; Instrucción sobre libertad cristiana y liberación 98) y la Iglesia latinoamericana ha plasmado en Medellin (6, Pastoral popular) y Puebla (444-469). ${ }^{5}$

Nuestra hipótesis de trabajo es que en los EE. deberá reflejarse, de algún modo, la religiosidad popular de Ignacio y de su tiempo. Para verificarlo examinaremos las posibles conexiones entre los EE. y la religiosidad popular a partir del mismo texto autógrafo de los EE.6

\section{Elementos de religiosidad popular presentes en los Ejercicios}

Podemos agnupar los elementos de la religiosidad popular presentes en los EE. en tres grandes capítulos: elementos doctrinales, elementos metodologicos y elementos ambientales.

\subsection{Elementos doctrinales}

La teologia subyacente a las exposiciones doctrinales de los EE. es prevalentemente popular. Corresponde a la fe del pueblo sencillo, sin sutilezas de erudición teologica académica. Refleja simplemente la piedad popular de Ignacio.

La cristología de los EE. es, segin Hugo Rahner, escotista. ${ }^{7}$ Sin embargo, sin negar esta tesis, sino radicalizándola aún, más, podemos afirmar que la cristología básica y fundamental de los EE. es la típica franciscana, profundamente arraigada en el pueblo y concretamente en el ambiente religioso de Guipuzcoa y Castilla que vivió Ignacio en su familia, juventud y mocedades. Esto aparece sobre todo en la meditación del nacimiento:

El primer preámbulo es la historia: y será aquf, cómo desde Nazaret salieron Nuestra Seffora grávida quasi de nueve meses, como se puede meditar plamente, asentada en una asna, y Joseph y una ancila, llevando un buey para ir a Bethlém, a pagar el tributo que César echó en todas aquellas tierras (EE.111; veáse también EE.114). 
Se puede decir que todos los misterios de la vida de Cristo están profundamente marcados por un acercamiento a la humanidad de Jesús, al Jesús de la historia, al Jesús histórico en formulación modema. Este redescubrimiento de la humanidad de Jesús es típico de la religiosidad medieval, como reacción a una cristologla oficial, un tanto hierática y desencarnada, ortodoxa pero alejada del pueblo. ${ }^{8}$ Este franciscanismo popular fue el que impulsó a Ignacio a imitar a San Francisco, a visitar Tierra Santa y a querer quedarse allá.

Esta humanidad de Jesús nunca es vista desde una mentalidad racionalista o moderna Está siempre unida a la divinidad, aunque ésta se esconda en la pasión (EE.196). Por esto Jesús es el "Eterno Seflor de todas las cosas" (EE. 98), "Cristo Nuestro Sefior" ("EE. 91,95,135...), "El Criador y Seffor" (EE. 15,16...).9

Franciscano y popular es el coloquio de los pecados ante Cristo crucificado (EE. 53), lleno de realismo y dramatismo imaginativo. Popular es también la contemplación de Cristo resucitado a Nuestra Señora (EE. 218,219) defendida por Ignacio a pesar del silencio de los evangelios (EE. 299). También es popular la aparición de Jesús resucitado a José de Arimatea "como píamente se medita y se lee en la vida de los santos" (EE. 310).

La escatologla, que juega un fuerte papel en toda la dinámica de los EE., es también popular. ${ }^{10} \mathrm{La}$ visión del infiemo, tan llena de realismo, reproduce sin duda la predicación tradicional de aquel tiempo (EE. 65-70). También corresponde a la visión popular la situación de "cada uno que por un pecado mortal es ido al infiemo" (EE. 52). El papel de la muerte y del jucio para decidir en una elección importante en la vida (EE. 186-187; 340-341) también corresponde al imaginario religioso popular, y seguramente tiene presente la práctica testamentaria de la época: en la hora de la muerte se reconocen errores y fallos, se pide perdón a la familia, se enderezan entuertos. La insistencia en el temor de Dios (EE. 65), no sólo en el temor filial, sino incluso el servil (EE. 370), también relleja un sentimento religioso profundamente arraigado en el pueblo, muy alejado de las discusiones eruditas sobre "el puro amor de Dios"...

La antropología teológica de los EE. es también popular, con claros influjos platónicos, que siempre han sido más populares que las disquisiciones aristotelicas sobre materia y forma: 11

Considerar mi ánima ser encarcerada en este cuerpo corruptible y todo el composito en este valle, como desterrado entre brutos animales (EE. 47).

También es popular y elemental la moral teológica, fuertemente anclada en la antropolog [a: el examen (EE. 32-42), el modo de orar sobre los mandamientos (EE. 238-243), pecados mortales (EE. 244), potencias del alma (EE. 246) y cinco sentidos 
comporales (EE. 247-248). Corresponden a la religiosidad elemental del pueblo y a la catequesis medieval. Ninguna sutileza sobre los dones del Esplritu ni sobre las bienaventuranzas. Estos exámenes y modos de orar, recomendados para los rudos y de poca capacidad (EE. 18), no se limitan a ellos, sino que deben ser enseñados a lodos los ejercitantes.

Finalmente la angelologla de todos los EE, es sumamente popular. 12 Todos los EE. están atravesados por la lucha entre ángeles y demonios, entre buenos y malos espiritus que se disputan el campo del ejercitante (EE. 32 y sobre todo las reglas para discemir espiritus EE. 313-327 y 328-336).

Desde el pecado de los ângeles (EE. 50) la humanidad se ve sometida a una lucha que hallará en la meditación de las dos banderas su expresión simbólica privilegiada de Babilonia y Jerusalén (EE. 136-148). El "enemigo" nos somete continuamente a sus astucias, nos tienta, nos lanza redes y cadenas, se transfigura sub angelo lucis (EE. 10, 12, 32, 314, 315, 318, 320, 325, 326, 327, 329, 331, 332, 333, 334, 335. $336,345,349,350)$. Frente a él. Dios y sus ángeles nos atraen continuamente y mueven suavemente el alma hacia el bien (EE. 314, 315, 316, 329, 331, 333, 335, 336) y nos soportan, guardan y ruegan por nosotros (EE. 60).

Esta visión dramática de ángeles y demonios, que la iconografla del románico y del gótico plasmó maravillosamente, es eminentemente popular, alejada no ya de los problemas modemos de la psicología profunda y de la exégesis crítica, sino incluso de las elucubraciones escolásticas de la época, de las que sólo se hallan algunos vestigios, seguramente fruto de los estudios posteriores de Ignacio en París (por ejemplo en EE. 330, 331).

Estos elementos doctrinales, a los que se podrían afiadir algunos otros de menor importancia (el campo damaceno en el que fue creado Adán (EE. 51), el ejemplo de Joaquín y Ana al repartir sus bienes (EE. 344...),. reflejan todo el mundo de la religiosidad popular que vivió Ignacio y que constituye el marco teológico en el cual se desarrollan los EE. El que las intuiciones espirituales y místicas de Ignacio desborden este maco y tengan una validez que va más allá de su conceplualización teológica no debe hacernos olvidar este sustrato básico de la religiosidad popular que impregna toda su exposición doctrinal.

Esclarecer y fundamentar históricamente cada una de estas afimaciones desborda los límites de estas páginas, que se limitan a constatar el hecho y a descubrir las implicaciones teológicas y pastorales del mismo.

\subsection{Elementos metodológicos}

Llamamos elementos metodologicos a las formas de exponer la doctrina y los temas espirituales, el modo y orden (EE. 2). Estas formas expresan muchas veces, más que los mismos contenidos doctrinales, su carácter popular.

La religiosidad popular se caracteriza, entre otras cosas, por una serie de notas 
formales, entre las que destacamos las siguientes: 13 es una religiosidad muy ligada a los sentidos, a lo imaginativo y a todo el mundo somático y cósmico; su estilo es acentuadamente simbólico, procede por ejemplos, comparaciones y tipologfas; sus expresiones devocionales se caracterizan por la exuberancia de los sentimientos que estallan en manifestaciones de júbilo o de dolor, y se nutre de devociones afectivas; y gusta de lo iterativo, del ritmo litánico y repetitivo. Veamos cómo estos elementos metodologicos son incorporados en los EE. ignacianos.

\subsubsection{Religiosidad sensorial y cosmica}

Son tantos los elementos sensoriales y cósmicos en los EE. que la simple enumeración de sus diferentes tipos nos muestra su significación: la importancia que se da a la oración vocal (EE. 1,2...); la especificación de las diversas posturas corporales: de rodillas, de pie, paseando, supino rostro arriba, la reverencia debida (EE. 2,75,76,252); la mención explícita de la penitencia externa (EE. 82-85); la atención a los "temporales buenos o adversos:" oscuridad, claridad, frío, calor... (EE. 130...) la composición viendo el lugar, que varía según sea una contemplación visible $o$ invisible (EE.47) y que Ignacio va especificando en cada caso (EE. 103. $112,138,140,143,151,192,202,220,232$, cfr. 53); la aplicación de sentidos (EE. 65-70, 121-125); la estructuración tripartita de la contemplación: ver las personas, escuchar las palabras que dicen, mirar lo que hacen (EE. 106-108; 114-116; 194); la importancia dada al ordenarse en el comer (EE. 210-217).

Todos estos elementos sensoriales y cósmicos son introducidos en el texto, de forma que no hay página de los EE. que no esté impregnada de esta religiosidad que busca ver, sentir, gustar, tocar. La misma experiencia espiritual de los EE. es formulada en términos sensoriales: "el sentir y gustar de las cosas intemamente" (EE. 2).

\subsubsection{Estilo simbólico y tipológico}

Resulta sorprendente en una lectura atenta de los EE. la cantidad enorme de comparaciones y ejemplos que se proponen tanto al que los da como al ejercitante. Enumeremos algunos de ellos: tanto el que da los EE. como el que los recibe deben estar indiferentes como el fiel de la balanza, "como un peso" (EE. 15,179); el coloquio debe hacerse como un amigo habla a otro, o como un siervo a su seflor (EE. 53); en la meditación de los pecados propios se habla de disminuirse por ejemplo, comparándose con todos los hombres, con los ángeles y santos, con Dios, mirándose como llaga y postema (EE. 58), comparando los antributos de Dios con los propios (EE. 59); en la segunda adición de la primera semana, el ejercitante se ha de poner ejemplos como el caballero avergonzado ante el rey o como los encarcelados ante el juez (EE. 74); el llamamiento del rey temporal es un ejemplo que ayuda a contemplar el rey eternal (EE. 91-97); Cristo nos da ejemplo tanto para el estado de custodia de los mandamientos como para el de perfección evangélica (EE. 135); el resucitado consuela, como unos amigos consuelan a otros (EE. 224); todos los bienes descienden de arriba as ( como del sol descienden los rayos, de la fuente las 
aguas (EE.237); el enemigo actúa como mujer (EE. 325), como vano enamorado (EE. 326), como un caudillo (EE. 327); el ángel bueno, en los que proceden de bien en mejor, toca al alma suavemente como gota de agua en una esponja, mientras que el ángel malo toca con sonido como cuando la gota de agua cae sobre la piedra (EE. 335); el escrupuloso cree ser pecado lo que no es, como acaece cuando uno pisa accidentalmente una cruz de paja y cree que ha pecado (EE. 346).

Afiadamos a esta enumeración de ejemplos la preocupación ignaciana por tipificar situaciones y problemas. El caso más clásico lo constituyen las meditaciones de las dos banderas (EE. 136), la de tres binarios (EE. 150) y las tres maneras de humildad (EE. 164). Las alusiones a los santos y a sus vidas, como upos de vida cristiana ejemplar (EE. 100), refuerzan esta tendencia ejemplificadora de Ignacio.

Pero hay otros ejemplos de este deseo de Ignacio de concretar temas: el examen particular y cotidiano con sus adiciones: poner la mano en el pecho ante cada caída, doliéndose de ello, y el anotar las faltas cometidas en unas líneas previamente establecidas (EE. 24-31); el examen de conciencia centrado en pensamiento, palabra y obra (EE. 33-42); el mirar la casa donde he vivido, la conversación que he tenido con otros, el oficio ejercilado, para recordar los pecados personales (EE. 56); el primer modo de orar sobre los mandamientos, los siete pecados capitales, las tres potencias del alma, los cinco sentidos corporales (EE. 238-247).

Este deseo de concreción y plasticidad llega a extremos notables, como en el de la meditación de la encarnación donde nos presenta un tríptico que parece un auténtico retablo gotico: las tres personas divinas que miran la redondez de la tierra, los hombres que descienden al infiemo, y el ángel $S$. Gabriel que es enviado a Nuestra Señora (EE. 102).

\subsubsection{Exuberancia afectiva}

En los EE. existe un notable clima afectivo que contrasta con las acusaciones de racionalismo e intelectualismo que se han lanzado contra el método ignaciano: lágrimas de dolor por los pecados, de gozo, de compasión por el Cristo doloroso o de exultación pascual (EE. 55, 87, 89, 195, 221, 316); "esclamación admirativa con crescido afecto" ante el hecho asombroso de que Dios y sus creaturas me hayan dejado con vida después del pecado (EE. 60); se recomiendan oraciones tradicionales (Pater, Ave, Credo) pero también otras populares llenas de devoción y afecto, como el Anima Christi (EE. 147, 63, 253, 258) y la Salve Regina (EE. 253-258); el mismo uso de penitencias externas (EE. 82-87) supone un clima de entusiasmo religioso y de afecto poco común en la vida ordinaria.

¿Quién no recuerda, al leer los textos ignacianos, el fervor medieval de las procesiones de penitentes y de flagelantes, o las peregrinaciones y romcrías a santuarios de santos o de Nuestra Señora, la devoción a las devotas imágenes de la Piedad o el canto solemne de las secuencias litúrgicas? 


\subsubsection{Repetición y ritmo}

Dentro de la metodologia popular llama la atención la importancia que Ignacio da las repeticiones (EE. 62, 99, 118, 120, 132, 148...) y resúmenes (EE. 64) para interiorizar más los sentimientos y profundizar en ellos.

El método de oración por anhélitos o por compás (EE. 258) incita a rezar al ritmo de la respiración. Es conocida en la espiritualidad tradicional el impacto popular de estas repeticiones acompasadas, que está en la base no sólo de la oración hesicasta, sino de la más popular de jaculatorias y letanias. ${ }^{14}$ La misma oración del Anima Christi, a la que tan aficionado es Ignacio, es en el fondo una letanía cristocéntrica.

Resumiendo todo lo visto podemos concluir que el modo de exponer los diferentes temas de los EE. asume elementos típicos de la religiosidad popular, no sólo de la época de Ignacio, sino de todos los tiempos. Una comparación con otros tratados de oración de la época nos confurmaría que el estilo de los EE. es mucho más popular, sencillo y sensorial que, por ejemplo, el de la mística flamenca y renana, mucho más especulativo y metafísico.

\subsection{Elementos ambientales}

A lo largo de los EE. van apareciendo, como de paso, alusiones a prácticas religiosas populares: alusión a la tendencia a hacer votos y promesas (EE. $14 \mathrm{cf}$. 15); referencia a bulas de cruzadas e indulgencias (EE.42); citas de oraciones populares, sobre todo, como ya hemos visto el Anima Christi y la Salve Regina; mención de la penitencia externa "trayendo cilicios o sogas o barras de hierro sobre las carnes, flagelándose o llagándose" (EE. 85); recomendación de libros como la Imitación de Cristo y las vidas de santos (EE. 100); referencia a las siete palabras de Cristo en la cruz (EE. 297) que sin duda alude a los sermones del tiempo de pasión.

Pero sin duda alguna, las "Reglas para sentir con la Iglesia" (EE. 352-370) constituyen el documento más rico en alusiones a la religiosidad popular. Evidentemente la perspectiva es antierasmista y antiprotestante, como hemos indicado al comienzo, pero refleja una gran simpatia, para con estas expresiones de la religiosidad popular que fueron practicadas en parte por el mismo Ignacio. No nos detendremos en los elementos que podríamos llamar oficiales de piedad (sacramentos, horas canónicas, estado religioso), sino en los más populares: cantos y largas oraciones (EE. 355); reliquias de santos, estaciones, peregrinaciones, indulgencias, perdonanzas, cruzadas, candelas encendidas (EE. 358); ayunos, penitencias internas y externas, abstinencias (EE. 359); ornamentos, edificios, imágenes (EE. 360); comparaciones entre santos, que sin duda nacian del fervor de sus devotos cofrades, pero que degeneraban en disputas (EE. 364).

Finalmente, como luego veremos, se habla explícitamente de "la gente menuda" (EE. 362), del "pueblo menudo" (EE. 367) del "pueblo" (EE. 368).

Hay, pues, una constante referencia a la religiosidad popular del tiempo, verdadero marco tcológico y espiritual en el cual se encuadran los EE. EI paisaje religioso y 
espiritual que está en el fondo de los EE. es el de la religiosidad popular. Esto parece innegable, cualquiera que sean sus causas e intenciones o las interpretaciones que podamos dar del hecho.

\subsection{Postura ignaciana frente a la religiosidad popular}

¿Cómo actúa Ignacio frente a esta religiosidad popular ambiental? ¿La asume sin añadiduras? ¿La defiende?

Podríamos afirnar que la postura ignaciana es muy matizada y, como todas las suyas, muy ponderada. Asume religiosidad popular, incluso la alaba ("alabar candelas encendidas"), pero al mismo tiempo la purifica, la profundiza, la orienta, de algún modo la transforma. No cae en el sentimentalismo ni cede a la verborrea, sino que se mantiene siempre en una gran sobriedad (EE.2).

La piedad medieval hacia la humanidad de Jesús es asumida, pero con una orientación que trasciende la Devotio moderna y se encamina hacia el seguimiento. La meditación del reino tipifica este modo de proceder.

Las meditaciones de la vida de Cristo se enriquecen con las presentaciones bíblicas de los "misterios de la vida de Cristo Nuestro Seffor (EE. 261-312) con abundantes citas textuales del evangelio.

La oración vocal y los mismos exámenes de conciencia conducen a una verdadera interiorización, purificación e integración espiritual. La imaginación y los sentidos en meditaciones como la aplicación de sentidos conducen a una profundización incluso mística de los sentidos espirituales, hasta llegar a oler y gustar "la infínita suavidad y dulzura de la divinidad" (EE. 124). Los elementos populares de la psicología y antropología religiosas y de la angelología tradicional se articulan para iniciar en una verdadera discreción de espéritus y en una elección realmente evangélica. También los datos de la escatologla popular son asumidos en orden a una conversión auténtica y a una iniciación en el discemimiento espiritual.

Las dimensiones somáticas y cósmicas, todas las mediaciones creaturales son finamente reguladas en adiciones y anotaciones al servicio de la oración y de la elección. Un caso típico es el de la penitencia externa aflictiva. Esta praxis de origen claramente medieval (la penitencia de la Iglesia primitiva y de la monástica primera es más bien de abstención), conducía a ambiguos entusiasmos, a unos fervores casi masoquistas y en todo caso necesitados de discernimiento. Ignacio en su célebre adición 10 profundiza esta praxis, insistiendo en sus motivaciones espirituales, moderando sus excesos, interiorizando sus efectos (EE. 82-87).

Todo el rico mundo de la sensibilidad, de los afectos, emociones y sentimientos, es asumido, orientado, interiorizado, purificado. Ignacio sabe que el hombre se mueve por el corazón y el sentimiento. Lo que hace es ordenarlo, no destruirlo.

Las medilaciones y contemplaciones buscan un compromiso (vg. EE. 53), un reflectir para sacar provecho (vg. EE. 107, 108..). Toda la forma y estructura (EE. $1,4,12,72,73,90 .$.$) , que podría parecer casi un rígido ritual, se acomoda y adapta a$ cada persona y caso (EE. 2,4,8.9.10.17..). 
Por todo ello las "Reglas para sentir con la Iglesia" son mucho más que una defensa coyuntural de la religiosidad popular en unos momentos en que el protestantismo naciente la atacaba. Son una defensa intrínseca de los valores de la religiosidad popular, con la convicción de que en ella se contiene el sensus fidelium, el sentido de la fe del pueblo de Dios. También le preocupa no escandalizar ni turbar la fe sencilla del "pueblo menudo." Ello responde a una convicción cvangélica: a cllos han sido revelados los misterios del reino (Mt. 11,25) y ¡ay de quien les escandalice! (Mt. 18,1-6). En el fondo hay un sentido de fe profundo de que Cristo y la Iglesia, su esposa, están unidos por el mismo Espíritu (EE. 365).

En Ignacio hay sensibilidad para lo popular no sólo porque corresponde a su propia religiosidad de cristiano popular, sino quizás por una profunda intuición de que el mundo popular ha mantenido, más que otros sectores, un sentido antropológico integral, una fe encarnada en las mediaciones creaturales y un profundo sentido de Dios. El mundo que se estructura a partir del siglo XVI y al cual pertenece por origen el protestantismo, es mucho más racionalista e individualista y mucho menos sensible a las mediaciones ( $\mathrm{Y}$ a algunos mediadores...). De ahí brota una cierta dificultad del mundo moderno y secular para entrar dentro de la cosmovisión de los EE. de Ignacio.

Podemos acabar esta reflexión con un texto de Pablo VI en Evangelii muntiandi sobre la piedad popular.

Refleja una sed de Dios que solamente los pobres y sencillos pueden conocer. Hace capaz de generosidad y sacrificio hasta el heroísmo, cuando se trata de manifestar la fe. Comporta un sentido hondo de los atributos divinos: la patemidad de Dios, la providencia, la presencia amorosa y constante. Engendra actitudes interiores que raramente pueden observarse en el mismo grado en que no poseen esta religiosidad: paciencia, sentido de la cruz en la vida cotidiana, desapego, aceptación de los demás, devoción. Teniendo en cuenta esos aspectos, la llamamos gustosamente "piedad popular," es decir, religión del pueblo, más bien que religiosidad (EN 48).

\section{Conclusiones e interrogantes}

Después de este rápido recorrido por todo el texto de los EE. para descubrir los diversos elementos de la religiosidad popular presentes en él, ¿qué conclusiones podemos sacar?

Parece evidente que la religiosidad popular invade continuamente el itincrario de los EE., tanto en sus aspectos doctrinales como metodológicos y ambientales. ¿Lo hizo Ignacio conscientemente o más bien rellejó su propio mundo religioso? Nos inclinamos a esto último. Ignacio era un hombre medieval, que vivía intensamente la religión del pueblo, como consta a través de su Autobiografla y de los modernos estudios históricos ignacianos (Leturia, Wolter, H. Rahner, Dalmases, Villoslada, Dumeige, Tellechea...). Los textos menos populares de los EE. son los que corresponden a épocas posteriores y reflejan preocupaciones diferentes y un estilo 
más académico y conceptual: principio y fundamento, reglas para la elccción, contemplación para alcanzar amor, reglas para sentir con la Iglesia.

Pero como hemos intentado demostrar, este trasfondo popular es orientado hábilmente por Ignacio para sus fines específicos: quilar las aficiones desordenadas, buscar la voluntad de Dios, elegir lo que más conduce al seguimiento del rey etemal. Para esto realiza un trabajo de profundización, interiorización, purilicación e integración, que puede servir de modelo para todos cuantos desean asumir,angelizar y purificar la religiosidad popular en nuestros días.

Affadamos a esto la preocupación de Ignacio por respetar el "pucblo menudo," no escandalizarlo, no turbarlo.

La conclusión de todo ello es que los EE. no constituyen un prototipo de espritualidad culta, académica y erudita, sino más bien un modelo de espirilualidad fuertemente anclada en lo popular. Este es el material básico sobre el que Ignacio estructurará su propia metodología espiritual.

De aquí surgen algunos interrogantes teóricos y prácticos. ¿No habrá habido, cn el correr de los siglos, un deslizamiento lento, pero cierto de este uansfondo popular de los EE. hacia una orientación más aristocrática y elitista de los EE., tanto en su concepción como en su praxis pastoral? ¿No habrá sido este cambio paralelo al que ha sucedido el irse propiciando con el tiempo una concepción cada vez menos afectiva y mística de los EE. y cada vez más voluntarista y racionalista? ¿No habrá sido ahogada esta vivencia más sencilla y popular de los EE. por una exégesis dcl texto desde categorías más modernas, técnicas y críticas?

Estas cuestiones tienen consecuencias prácticas. ¿No habrcmos abandonado con demasiada facilidad los EE. a los sectores populares, por creerlos incapaces de ellos, limitándonos a sectores más cultivados y elevados, espiritual, tcológica y, a mcnudo, económicamente? ¿Muchas "adaptaciones" de los EE. a sectores populares no olvidan que, en su origen, lo popular ya está presente en los EE.? ¿No se debería, tol vez, partir hoy de la religiosidad popular de los sectores populares, para desde esca base iniciar el itinerario ignaciano espiritual?

Evidentemente el mismo Ignacio supone, como hemos visto al comienzo, que un mínimo de capacidad humana y de formación cristiana es requerida para entrar en $\mathrm{EE}$. (EE. 18), pero ¿no hay una mayor sintonía con los EE. en muchos sectores populares que en sectores del mundo más "modemo," culto y acomodado, pero que ha perdido muchas dimensiones humanas y evangélicas, todavía presentes en sectores populares? No será la falta de cultura, sino la falta de subjecto lo que limita el uso de los EE.

La religiosidad popular, en últumo término, forma parte del sensus fidelium del pueblo de Dios (LG. 12) y posee un innegable "potencial evangclizador" (Puebla 1147). Tenerlo presente y aprovecharlo, forma parte de la sabiduría evangélica. $Y$ las experiencias ya existentes de una praxis de los EE. en sectores populares en América Latina indica que el camino está ya abierto.

Concluyamos con una reflexión coyuntural. Se ha notado que existe una con- 
naturalidad entre los grandes temas e inspiración de la teología de la libcración y los de los EE.: partir de la realidad y en concreto de la realidad del pecado, la exigcncia de conversión, el tema del reino, el seguimiento, la necesidad de oplar, la contemplación en la acción, la importancia del Jesús histórico, la acentuación de la pobreza, etc. Ahora podemos affadir que en estos temas se pucde incluir otro: la preocupación por la religión del pueblo pobre y sencillo.

\section{NOTAS}

1. Remitimos a los siguientes estudios de M. de Franca Miranda, "Sentir com a Igreja," Perspectiva teologica, 1986, 18, 315-342; F. Segura, "Las reglas ignacianas para scrntir con la Iglesia," Manresa, 1986, S8, 199-208; y a la obra conjunta "Sentire curn Ecclesia," CIS, Roma, 1986, donde se hallará ulterior bibliografla.

2. "Nadal define la ejecutoria religiosa de If́igo con una expresión de gran modemidad: populariter christianus. Hoy, tras unos ramalazos puritanos y de gabinete contra la religiosidad popular, comenzamos a descubrir valores ocultos bajo la hojarasca, sentido hondo debajo de la exicrioridad," J.L Tellechea, Ignacio de Loyola, solo y a pie, Madrid, 1986, 90.

3. P. de Leturia, El gentilhombre In̈go Lopez de Loyola, Barcelona, 19492; H. Rahner, Ignacio de Loyola y su historica formación espiritual, Santander, 1955; C. de Dalmases, El podre meesiro Ignacio de Loyola, Madrid, 1980; J.I. Tellechea, "También data de entonces el asentamiento de indudables vetas franciscanas en el espíriu de Iñigo," o.c., 55.

4. I. Iparraguirre, Próetica de las Ejercicios de S. Ignacio de Loyola en vida de su autor, Vol. I. Roma, 1943.

5. Ls bibliografia sobre este tema es inmensa. Citemos tan sólo algunas obras signifjcativas: Equipo SELADOC, Religiasidad popular, Salamanca, 1976; J.M.R. Tillard, Foi populaire, foi sawanse, Paris, 1976; S. Galilea, Catolicismo popular, Sao Paulo, 1979; D. Irarrazaval, "Mcdellín y Pucbla: religiosidad popular," P\&ginas, 1979, 4, 19-49: H. E. Groenen, "Povo, religiao do povo c papcl da Igreja," REA,. 1979. 39, 435-465; V. Codina, "La religiosidad popular a debate," Actualidad bibliogrofica, 1977, 28, 321-332; "La religiosidad popular, "Cociliwn, 1986, 206; L. Maldonado, Introducción a la religiosidad popular, Santander, 1985.

6. Este trabajo complementa mis otros estudios anteriores: "Claves para una hermeneúlica de los Ejercicios," Manresa, 1976, 48, 51-72; "Estructura iniciática de los Ejercicios," Manresa, 1977, 49, 291-307. Esto nos pemile dar por supuestos algunos temas alli ya tratados (vg. la clave medieval y pretridentina de Ignacio, las dimensiones simbólicas de la iniciación, elc.).

7. H. Rahner, "Die Christologie der Exersitien," en Ignarius von Loyolo als Menseh und Theologe, Freiburg, 1964, 251-311.

8. J. Lecleraq; F. Vandenbroucke; L Bouyer, La spiritualise du Moyen Age, París, 1961, 345-381. L Bolf, S. Franeisco de Asír, ternura y vigor, Santander, 1985.

9. M. Giuliani, "Die Nokre Crétateur el Rédcmpteur," Christus, 1959, 6, 329-344. Cfr. también "Claves para una hermeneútica de los Ejercicios," 1c. 62-64.

10. J. B. Libanio y M. C. Bingemer, Escarología cristiana, Buenos Aires, 1985.

11. J. Comblin, Tiempo de acción, Linna, 1986; y Antropología Cristian, Buenos Aires, 1985.

12. J. Martín Velasco; J. R. Busto; X. Pikaza, Angeles y demonios, Madrid, 1984.

13. L Maldonado, Religiasidad popular. Nasealgia de lo magico, Madrid, 1975; V. Codina, "Una teologla más simbólica y popular," Revista Latinoamericana de Teología, 1986, 8, 159-179.

14. Recordemos la importancia de las jaculatorias en el monacato primitivo y la tradición oriental de la oración de Jesús recogida en el Relato de un peregrino ruso. Veánse los estudios clásicos de I. Hausherr, Noms du Christ at vois d'oraison, Roma, 1960, y Hésychasme et prière, Roma, 1966. especialmente las páginas 134-153. 